\title{
Influence of railway loading on the performance of soil-filled masonry arch bridges
}

Levingshan Augusthus-Nelson PhD

Lecturer, School of Computing, Science and Engineering, University of Salford, Salford, UK (corresponding author: I.augusthusnelson@salford.ac.uk) (Orcid:0000-0003-3092-7635)

\section{Gareth M. Swift PhD}

Senior Lecturer, School of Earth and Environmental Sciences, University of Portsmouth, Portsmouth, UK

\section{Colin C. Smith PhD}

Senior Lecturer, Department of Civil and Structural Engineering,

University of Sheffield, Sheffield, UK
Matthew Gilbert PhD

Professor, Department of Civil and Structural Engineering, University of Sheffield, Sheffield, UK

\section{Clive Melbourne PhD}

Retired Professor of Structural Engineering, School of Computing, Science and Engineering, University of Salford, Salford, UK

There is a large number of masonry arch bridges on the rail networks in Europe and other parts of the world. However, the mode of response of masonry arch structures subjected to railway loading is little understood. To address this, an experimental study involving large-scale physical models of backfilled masonry arch bridges subjected to railway loading conditions was conducted. The study explored the influence of the rail track-bed system on bridge behaviour and load-carrying capacity. The tests results indicated that the track-bed system fundamentally alters the mode of response of the bridge system and significantly increases load-carrying capacity. Using the same test facility, load tests were also used to explore and characterise the behaviour and performance of damaged arch bridges. The results obtained suggest that, although there is likely to be a reduction in overall capacity, even a significantly damaged arch bridge can still perform adequately under loading. This has important implications for bridge owners and assessment engineers.

\section{Introduction}

The transport infrastructure of the UK and a large number of other countries still relies heavily on masonry arch bridges (Hughes and Blackler, 1997). It is estimated that there are approximately one million masonry arch spans around the world, the majority of which are now well in excess of 100 years old (Orbán, 2007). It is thus perhaps not surprising that many bridges are exhibiting signs of distress, either due to changing environmental conditions or significant changes in loading conditions (Orbán and Gutermann, 2009). Although these bridge structures are perceived to be long lived and resilient, there are still aspects of their fundamental behaviour that are poorly understood and this understanding needs to be significantly improved if they are to continue to form an integral part of our infrastructure (Brencich and De Francesco, 2004; Molins and Roca, 1998).

According to Orbán (2007) there are approximately 200000 masonry arch structures across Europe and about $60 \%$ of these carry railway traffic. To date, there has been very little research on the influence of railway loading on masonry arch behaviour, including the relationship between working loads and long-term load-carrying capacity.
The aim of the work reported in this paper was to investigate the influence of the rail track-bed system on the load-carrying capacity of masonry arches. The paper details full-scale tests carried out on a backfilled masonry arch bridge subjected to railway loading and results from tests on a bridge subjected to highway loading are provided for comparison. In addition, the paper reports on an ongoing investigation into the relationship between service loading and ultimate load capacity of these structures and also considers the residual capacity of damaged masonry arches, which has important implications for bridge owners and assessing engineers.

\section{Laboratory test programme}

\subsection{Test arrangement}

Tests were carried out on a number of $3 \mathrm{~m}$ span brickwork arch bridges constructed and backfilled in a purpose-made test chamber, the detailed design and construction of which is described elsewhere (Augusthus-Nelson et al., 2018; Swift et al., 2013). The test chamber permits essentially full-scale bridges to be tested under carefully controlled experimental conditions. Specifically, the boundary conditions provided mean that all tests can be conducted under essentially plane 
strain conditions in order to model the central region of a wide bridge effectively, assuming a two-dimensional response, with anticipated failure mechanisms involving the surrounding backfill not being constrained (Figure 1).

The tested bridges were constructed with segmental arch barrels with a nominal 4:1 span:rise ratio and were formed from class A engineering bricks. Alternate 'headers' were provided within each arch barrel to prevent ring separation as a possible failure mechanism. The abutments were fixed directly to the structural strong floor of the laboratory and were constructed from reinforced concrete. However, the skewbacks were free to move along a single mortar joint. This is a significant departure from the tests conducted previously in the Bolton Institute, where the abutments were fully fixed (Melbourne and Gilbert, 1995), and goes some way towards replicating what might be seen in practice.
However, most other details were similar to those employed previously at the University of Salford (Gilbert et al., 2007), allowing direct comparisons to be made as necessary. Figure 2 shows the general arrangement of the bridges as constructed.

Once the abutments and arch barrel had been constructed, backfill consisting of graded, crushed limestone was placed within the test chamber. To allow evaluation of the influence of the loading arrangement on the behaviour and capacity of the bridge, two different configurations were adopted. In the first configuration, general highway loading conditions were adopted (bridge EP1) while a simplified railway loading arrangement was adopted in the second configuration (bridge EP3). As such, the filling operations differed somewhat since the latter arrangement required the inclusion of a ballast layer and the former did not.

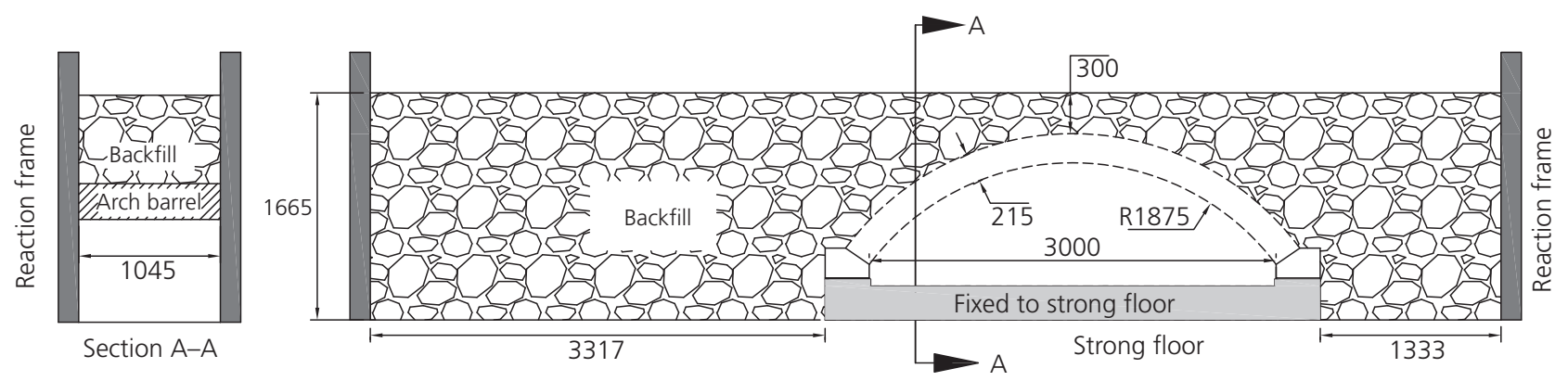

Figure 1. Test chamber in relation to the masonry arch barrel and abutments (dimensions in $\mathrm{mm}$ )

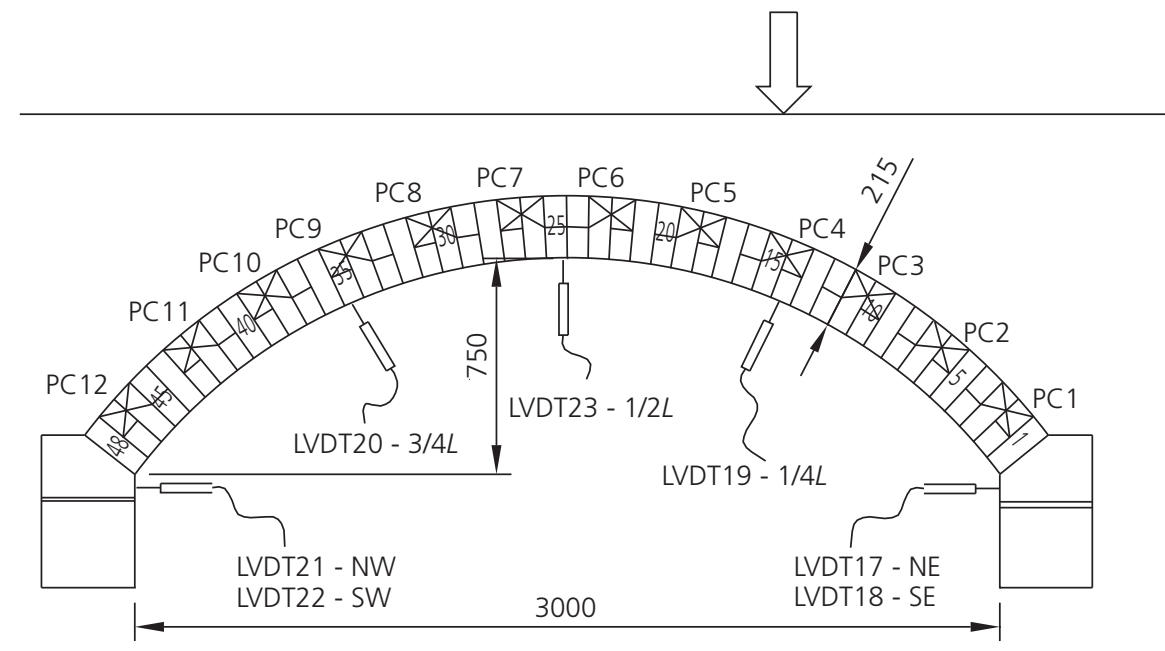

Figure 2. General arrangement of the masonry arch barrel and abutments, with the positions of pressure cells and LVDTs as indicated (dimensions in $\mathrm{mm}$ ) 
In the case of bridge EP1 (highway), MOT type 1 limestone backfill, commonly used for backfilling in the highway industry, was carefully placed in $120 \mathrm{~mm}$ thick layers up to $300 \mathrm{~mm}$ above crown level. The fill was placed and compacted to achieve a specified unit weight $\left(20 \mathrm{kN} / \mathrm{m}^{3}\right)$ using a $10 \cdot 5 \mathrm{kN}$ vibrating compaction plate. Samples of the fill were taken at regular intervals to measure the moisture content of the asplaced fill. In the case of EP3 (railway), it was important to be able to replicate as far as practicable a railway track-bed system. To this end, bridge EP3 was backfilled with limestone up to crown level (as with EP1). This was followed by two $150 \mathrm{~mm}$ thick granite ballast layers above crown level. The ballast was compacted in a similar manner to the limestone fill. The as-placed unit weight for this material was $16.4 \mathrm{kN} / \mathrm{m}^{3}$.

\subsection{Test sequence}

The sequences of the tests carried out on the two bridges are listed in Table 1. In each case, testing involved a number of phases ( $\mathrm{PH})$. An additional phase (PH3) was employed in the case of bridge EP3 to enable the influence of railway sleeper spacing to be investigated.

\subsection{Instrumentation}

Linear variable displacement transducers (LVDTs) orientated normal to the intrados of the arch were used to monitor deflection of the arch barrel through all stages of the tests. Although it was assumed that the test chamber was sufficiently stiff, LVDTs attached normal to the vertical external faces of the test chamber were used to monitor deflection of the

Table 1. Test sequences for bridge EP1 (subjected to highway loading) and EP3 (subjected to railway loading)

\begin{tabular}{|c|c|c|}
\hline Test phase & \multicolumn{2}{|c|}{ Test stage } \\
\hline \multicolumn{3}{|l|}{ EP1 } \\
\hline PRE & DC1 & $\begin{array}{l}\text { Monitoring gauges during de-centring } \\
\text { process }\end{array}$ \\
\hline \multirow[t]{2}{*}{$\mathrm{PH} 1$} & CYC1 & Cyclic loading regime ( $10^{6}$ cycles) \\
\hline & QS1 & Quasi-static loading regime \\
\hline \multirow[t]{3}{*}{$\mathrm{PH} 2$} & RA1 & Arch resetting procedure \\
\hline & CYC1 & Cyclic loading regime ( $10^{5}$ cycles) \\
\hline & QS1 & Quasi-static loading regime \\
\hline \multicolumn{3}{|r|}{ 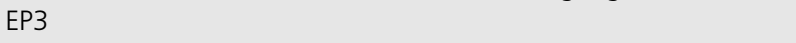 } \\
\hline PRE & DC1 & $\begin{array}{l}\text { Monitoring gauges during de-centring } \\
\text { process }\end{array}$ \\
\hline \multirow[t]{2}{*}{$\mathrm{PH} 1$} & CYC1 & Cyclic loading regime $\left(10^{6}\right.$ cycles $)$ \\
\hline & QS1 & Quasi-static loading regime \\
\hline \multirow[t]{3}{*}{$\mathrm{PH} 2$} & RA1 & Arch resetting procedure \\
\hline & CYC1 & Cyclic loading regime ( $10^{5}$ cycles $)$ \\
\hline & QS1 & Quasi-static loading regime \\
\hline \multirow[t]{3}{*}{ PH3 } & RA1 & $\begin{array}{l}\text { Arch resetting procedure; sleeper } \\
\text { spacing changed }\end{array}$ \\
\hline & CYC1 & Cyclic loading regime ( $10^{5}$ cycles) \\
\hline & QS1 & Quasi-static loading regime \\
\hline
\end{tabular}

chamber throughout the tests, the results of which confirmed this assumption. Electronic resistance strain gauges were positioned at selected locations on the extrados of the arch barrel to monitor movement across mortar joints and acoustic emission sensors were also used to monitor crack initiation and development within the arch. Within the extrados of the arch barrel, sockets were constructed during the arch construction. Twelve $500 \mathrm{kPa}$ earth pressure cells (PC1-PC12) were embedded within the sockets as indicated in Figure 2 such that the sensing face was flush with the arch extrados. A $50 \mathrm{~mm}$ thick layer of fine crushed limestone was placed on top of these pressure cells during backfilling in order to prevent damage during construction. This might have inevitably affected the pressure monitored due to, for example, arching effects. However, such issues are very hard to avoid in experimental work of this nature and therefore the pressure readings should be taken as indicative rather than definitive.

In addition to the array of traditional structural monitoring instrumentation, the transparent acrylic front face of the test chamber also allowed arch and soil deformations to be observed using image analysis software based on the principles of particle image velocimetry (PIV). This allowed soil displacement vectors to be obtained, which in turn enabled the soil failure mechanisms to be observed (White and Take, 2002).

\subsection{Loading arrangement}

The loading arrangement was designed to be sufficiently adaptable to allow application of both cyclic loading (representing working load conditions in an in-service bridge) and quasi-static loading (allowing determination of the bridge load-carrying capacity). The mechanical and hydraulic systems and the associated control system used in the tests are described in detail by Augusthus-Nelson et al. (2018). The following sections highlight essential elements of the system in the context of the tests reported here, first considering bridge EP1, subjected to highway loading, and then EP3, subjected to railway loading.

\subsubsection{EP1: cyclic loading arrangement}

To replicate working highway loading conditions, five loading beams formed from $975 \mathrm{~mm}$ long steel universal column (UC) sections of size $203 \times 203 \times 46 \mathrm{~mm}$ were placed transversely across the width of the surface of the backfill at $750 \mathrm{~mm}$ spacings, as shown in Figure 3(a). These were positioned vertically above the abutments, the quarter-spans and the crown. Steel sections were used in order to eliminate any variations that might be introduced due to material imperfections present with more traditional materials such as timber. Five servocontrolled actuators were used to apply a cyclic load, with the load applied directly to the loading beams. Using this arrangement, a peak cyclic load of $50 \mathrm{kN}$ with a frequency of $2 \mathrm{~Hz}$ was applied. A frequency of $2 \mathrm{~Hz}$ was selected to enable a 


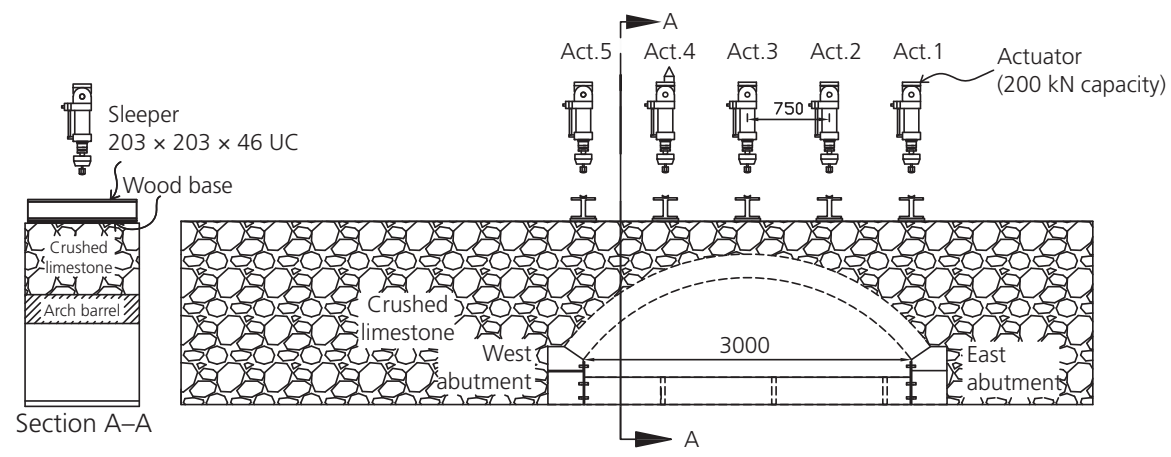

(a)

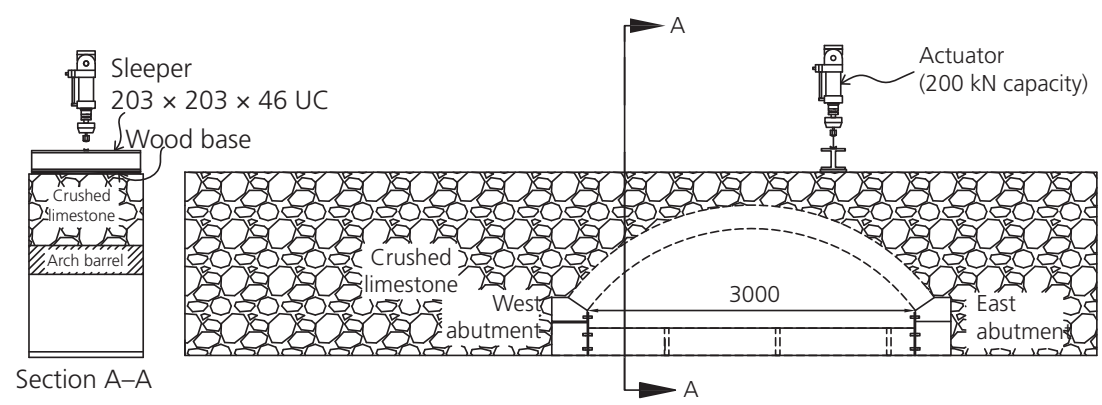

(b)

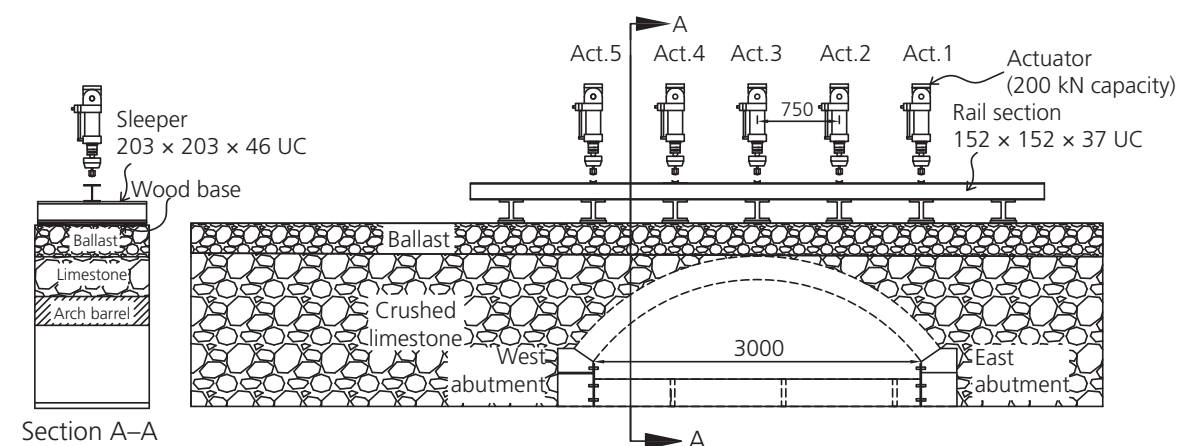

(c)

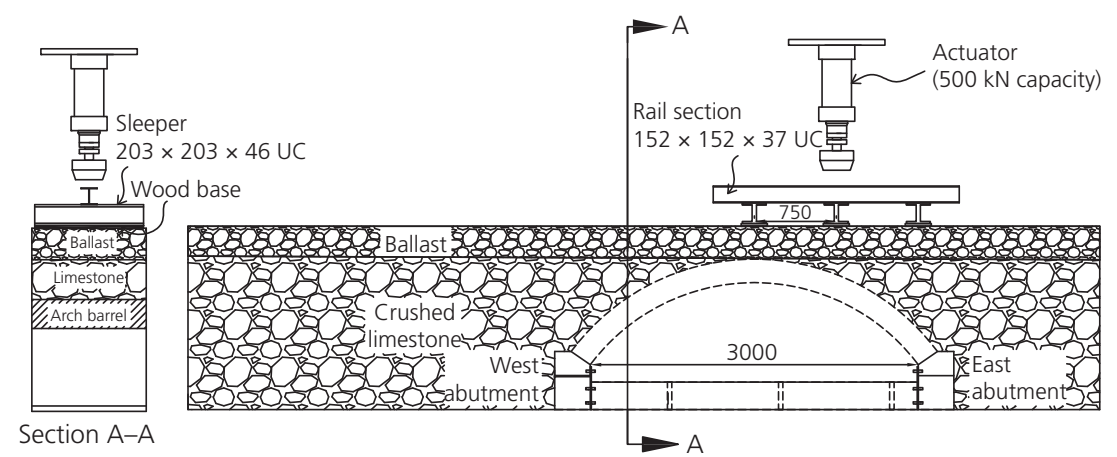

(d)

Figure 3. (a) Cyclic highway loading arrangement for EP1. (b) Quasi-static highway loading arrangement for EP1-PH1 and EP1-PH2. (c) Cyclic railway loading arrangement for EP3. (d) Quasi-static railway loading arrangement for EP3-PH1 and EP3-PH2 (spacing between sleepers reduced to $375 \mathrm{~mm}$ for EP3-PH3). All dimensions in $\mathrm{mm}$ 
sufficiently high number of cycles to be applied during the test time frame while ensuring that the effects of the loading could be captured by the available data acquisition system. The cyclic load was applied in the manner of a wave moving at constant velocity over the arch from the east abutment towards the west abutment. Each actuator applied the load in the form of a sine wave $180^{\circ}$ ahead of the next actuator, so that when the peak load level was reached on a given actuator the load applied on adjacent actuators was close to zero, as shown in Figure 4.

\subsubsection{EP1: quasi-static loading arrangement}

A single loading beam of the same type used for the cyclic loading test was placed above the quarter-span point and the arch was loaded to failure at this location using a single servocontrolled actuator, as shown in Figure 3(b). The quarter-span loading point was selected to be consistent with previous tests in the same rig and was considered to be close to the critical load location for a masonry arch bridge.

\subsubsection{EP3: cyclic loading arrangement}

To model the sleepers of a continuous rail track-bed system, seven steel loading beams of the same type used in bridge EP1 were placed transversely across the width of the surface of the ballast at $750 \mathrm{~mm}$ spacings. The selected spacing of $750 \mathrm{~mm}$ is within the range often used on UK railways, although the final choice of sleeper spacing would typically depend on factors such as loading conditions and the materials within the track-bed system (Network Rail, 2006; UIC, 1994). A sleeper was placed directly above the mid-span point, with three further sleepers placed at $750 \mathrm{~mm}$ spacings to each side, as shown in Figure 3(c). The rails were represented using a single

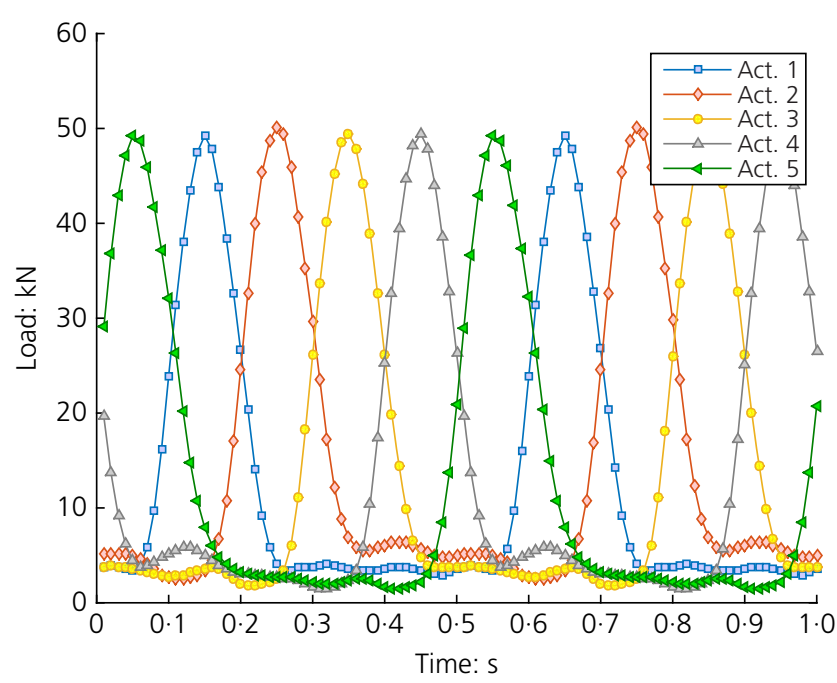

Figure 4. Cyclic loading regime showing applied force against time for each actuator (Act. 1 to Act. 5) steel UC section of size $152 \times 152 \times 37 \mathrm{~mm}$ (elastic and plastic section modulus of $273 \mathrm{~cm}^{3}$ and $309 \mathrm{~cm}^{3}$, respectively) running perpendicular to the sleepers. The beam properties were selected to be broadly equivalent to a $113 \mathrm{lb}(\approx 51 \mathrm{~kg})$ rail section (Kennedy et al., 2013), with the UC section preferred so as to avoid needlessly introducing additional variables that may make interpretation of test results difficult. Also, to simplify the situation, structural connections between the rail and the underlying sleepers were omitted. Five servo-controlled hydraulic actuators were used to apply the cyclic load, with the load being applied onto the longitudinal beam representing the rails at the locations shown in Figure 3(c). Using the rail track system, the same cyclic loading as used for bridge EP1, with a peak cyclic load of $50 \mathrm{kN}$ and a frequency of $2 \mathrm{~Hz}$, was applied.

\subsubsection{EP3: quasi-static loading arrangements}

A single servo-controlled hydraulic actuator of $500 \mathrm{kN}$ capacity was used to apply a vertical load as shown in Figure 3(d). Initially, three sleepers were utilised for the quasistatic test with a centre-to-centre spacing of $750 \mathrm{~mm}$, as in the cyclic tests, placed above the crown, the eastern quarter-point and above the eastern abutment (the remaining sleepers were removed from the test chamber). A shortened longitudinal beam section representing the rail was placed on top of these three sleepers and the actuator load was applied vertically to this directly above the central sleeper (i.e. at the quarter-point). In order to explore the influence of sleeper spacing on arch behaviour and capacity, a second quasi-static load test arrangement was later also undertaken using a reduced sleeper spacing of $375 \mathrm{~mm}$ (EP3-PH3).

\subsection{Loading regimes}

The cyclic loads were applied to replicate a period of service loading that the bridge might experience in practice, with peak load levels chosen to be less than half the anticipated ultimate limit state load. While this was not expected to lead to any damage to the masonry elements of the bridge, it was expected that the backfill in the vicinity of the loading beams (sleepers) would further densify beyond that which could be achieved through compaction during placement and that, as a consequence, the system stiffness would increase.

Once the cyclic loading phases were complete, the bridge was subjected to a quasi-static load test to failure at a rate that was sufficiently slow to ensure that inertial effects could be neglected.

\subsubsection{EP1: quasi-static loading regime}

Load was first applied using load control in $5 \mathrm{kN}$ increments, with images captured at the end of each increment (see Section 2.3). Once the bridge appeared to be close to failure, loading was changed to displacement control using $2 \mathrm{~mm}$ 
increments, based on the displacement measured by a LVDT on the intrados of the arch barrel at the quarter-point. This was to ensure that an adequate number of measurements were taken close to the point of failure.

\subsubsection{EP3: quasi-static loading regime}

This was a displacement-controlled test in which the displacement rate was selected to be $10 \mathrm{~mm} / \mathrm{h}$ up to the peak load, followed by an unload cycle, again displacement-controlled, at a rate of $60 \mathrm{~mm} / \mathrm{h}$. During the load test, images were taken at 2 min intervals to allow later study of the soil-structure interaction and soil deformations.

\subsection{Arch resetting procedure}

One of the aims of the study was to investigate the residual capacity of a damaged masonry arch bridge. This meant that, following a given loading phase, each bridge was prepared for the next phase by taking steps to restore the arch profile to as close to its original position as was practicable through the application of surface loads. In the case of bridge EP1, all five loading beams were placed on the backfill in the positions used for the cyclic load regime and a quasi-static load of $50 \mathrm{kN}$ was applied at each position in sequence, from west to east, in order to push the arch barrel towards its original, or near-original, profile. In the case of bridge EP3, this was achieved by putting back all five sleepers and the original longitudinal beam representing the rails (as used for the cyclic loading regimes), before activating all five actuators and carefully applying a quasi-static load of $50 \mathrm{kN}$ to the rail, starting from the east abutment in sequence. The resetting procedure only allowed a proportion of the distortion caused by the preceding load test to be removed, as indicated in Table 2 . For instance, for the first load test (EP3-PH1), of the $35 \mathrm{~mm}$ of deflection experienced at the quarter-span loaded in the

Table 2. Deformed profile of the arch barrel prior to quasi-static load test (positive and negative signs represent inward and outward directions, respectively)

\begin{tabular}{|cccccc} 
& \multicolumn{5}{c}{ Radial deflection: $\mathbf{m m}$} \\
Test phase & West & $3 / 4$ & $1 / 2$ & $1 / 4$ & East \\
\hline EP1 & & & & & \\
PH1-QS1-start & 0 & 0 & 0 & 0 & 0 \\
PH1-QS1-end & -4.99 & -30.18 & -13.42 & 22.60 & -0.13 \\
PH2-QS1-start & -5.26 & -9.95 & -1.56 & 9.52 & -0.15 \\
PH2-QS1-end & -5.91 & -34.56 & -13.62 & 28.27 & -0.18 \\
EP3 & & & & & \\
PH1-QS1-start & 0 & 0 & 0 & 0 & 0 \\
PH1-QS1-end & -30.53 & -7.32 & 13.67 & 32.62 & -0.38 \\
PH2-QS1-end & -30.63 & 3.87 & 30.13 & 24.69 & -0.38 \\
PH2-QS1-end & -36.69 & -22.76 & 51.14 & 52.27 & -0.62 \\
PH3-QS1-end & -35.70 & -6.05 & 54.49 & 40.11 & -0.62 \\
PH3-QS1-end & -36.88 & -31.14 & 55.33 & 55.26 & -0.87 \\
\hline
\end{tabular}

quasi-static test, less than $10 \mathrm{~mm}$ was recovered, as shown in Table 2. This meant that the initial profile of the arch at the start of a given phase of loading differed from the corresponding profile in the preceding phase.

Once this resetting procedure was completed, the cyclic loading regime followed by a quasi-static load test sequence was repeated. In EP3, the resetting procedure was repeated twice, allowing three load tests to be carried out on this arch. For the highway arch (EP1), only one resetting test procedure was carried out.

\section{Test results}

\subsection{Cyclic test results}

The cyclic loads were applied to replicate a period of service loading that the arches might experience in practice. Similar results were observed for EP1 and EP3. Figure 5 shows the results for EP3 and indicates that the backfilled soil material deformed and densified beyond that achieved through the construction process and was tending towards a steady state at the end of the cyclic loading phase.

Figure 6 shows the quarter-span deflection over the entire $10^{7}$ cycles. While there was general fluctuation about a mean, the mean level remained broadly consistent at around $0.2 \mathrm{~mm}$, with a fluctuation of approximately $\pm 0.5 \mathrm{~mm}$. These fluctuations are inferred to be due to movement on mortar joints within the arch barrel.

In summary, for both arches, cyclic loading did not modify the arch profile significantly but did result in densification of the backfill.

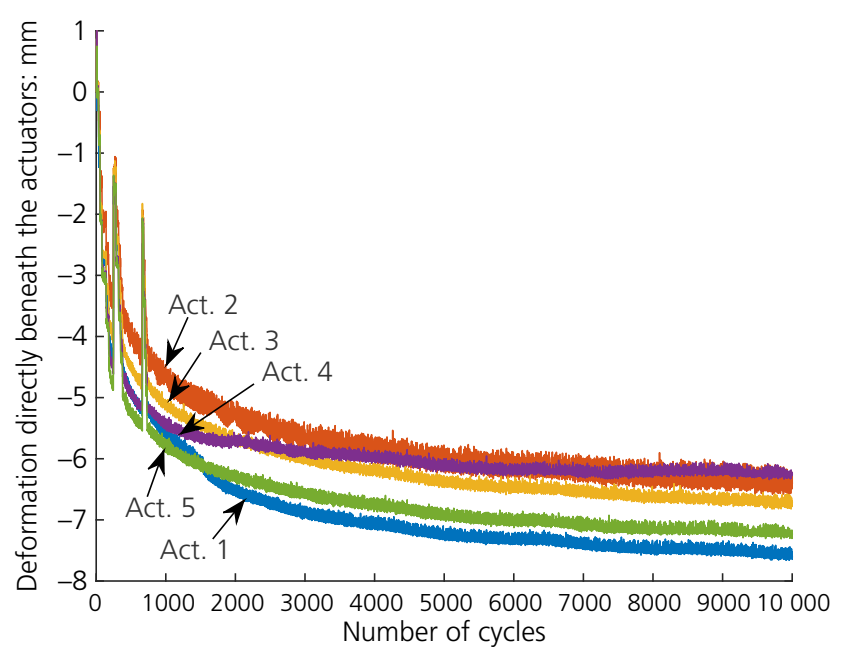

Figure 5. Top soil surface deformation of EP3 (the locations of the actuators (Act. 1 - Act. 5) are shown in Figure 3) 


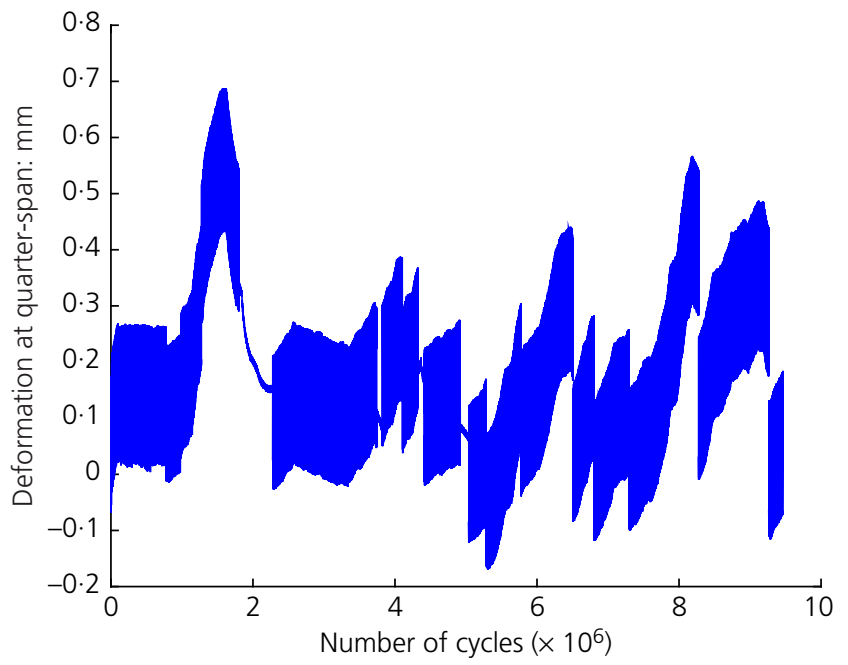

Figure 6. Bridge EP3 barrel deformation at quarter-span $\left(10^{7}\right.$ cycles)

\subsection{Quasi-static test results}

Figure 7(a) shows the results from load tests on the two arches. The $x$-axis plots the deflection of the arch barrel as measured on the intrados at the quarter-span, while the $y$-axis plots the applied load directly above the quarter-span. It can be seen that there was a significant difference in the capacity of the two arches. The load-deflection curve for the highway bridge immediately after $10^{6}$ cycles of cyclic loading shows a peak load of approximately $140 \mathrm{kN}$, while the load-deflection curve for the rail bridge at the same stage shows a maximum observed load of approximately $460 \mathrm{kN}$, although the load was still increasing when the test was stopped. Additionally, the initial stiff response continues to a significantly higher load in the rail loading case as compared with the highway loading.

A direct comparison of these two results suggests that a combination of load redistribution through the rail section and the underlying sleepers (as illustrated in Figures 7(a) and 7(b)) and the increased confinement of the soil mass because of this resulted in the significant difference in capacity of the two arches.

Once the arch had been reset, a second load test was undertaken (EP1-PH2 and EP3-PH2 for highway and rail loading, respectively). In the case of the rail arch, the load-carrying capacity continued to increase as the arch continued to deform, up to a maximum observed value of around $490 \mathrm{kN}$. In the case of the highway bridge, the capacity reduced for the damaged structure, to around $85 \%$ of the initial value. Although the arch had suffered significant distortion $(15.4 \mathrm{~mm}$ at the crown) at this stage, the residual capacity indicated by this test is still impressive.

Figure 7(b) shows the complete set of results for the three load tests carried out on the rail bridge EP3. EP3-PH3 relates to the third load test on the rail arch in which, in addition to the resetting of the failed arch and associated cyclic loading, the sleeper spacing was also reduced. There was a reduction in the load-carrying capacity of this damaged structure, with a

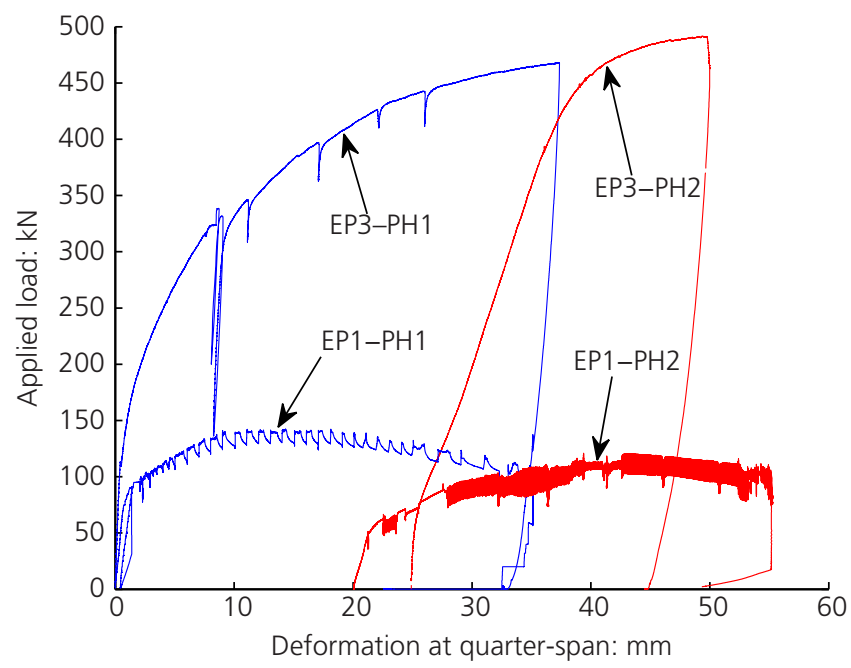

(a)

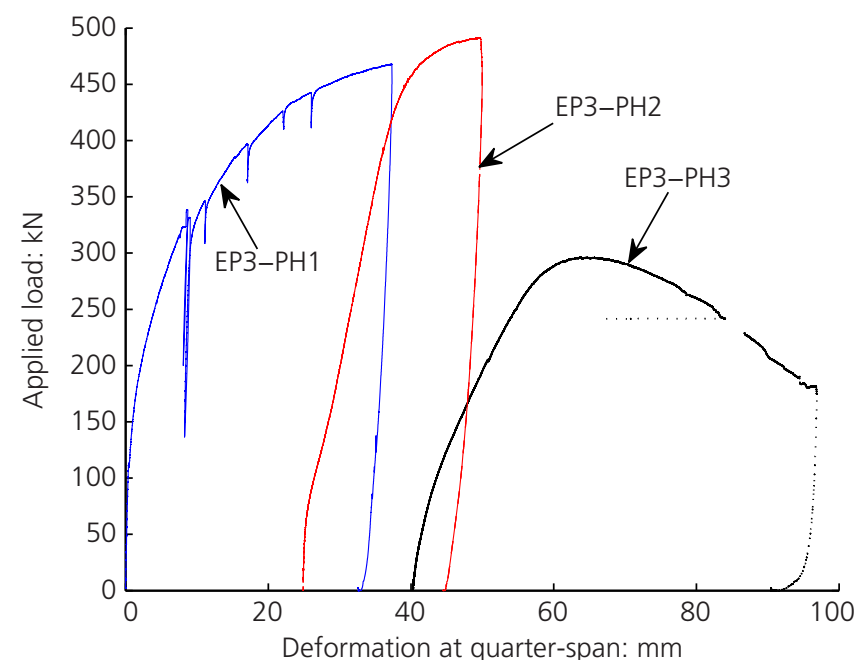

(b)

Figure 7. Applied load against deformation at the quarter-span. (a) Highway loading (EP1-PH1 and EP1-PH2) and railway loading (750 mm spacing between sleepers (EP3-PH1 and EP3-PH2)). (b) All three phases of railway loading (EP3-PH1 and EP3-PH2 with $750 \mathrm{~mm}$ sleeper spacing (upper bound) and EP3-PH3 with $375 \mathrm{~mm}$ sleeper spacing (lower bound)) 
peak load of around $275 \mathrm{kN}$, which is attributed to a reduction in load spreading through the soil as stresses were concentrated within a narrower zone, as indicated in Figure 8. Although it is unlikely that firm conclusions can be drawn from this one test, as other factors may also have had an influence, the

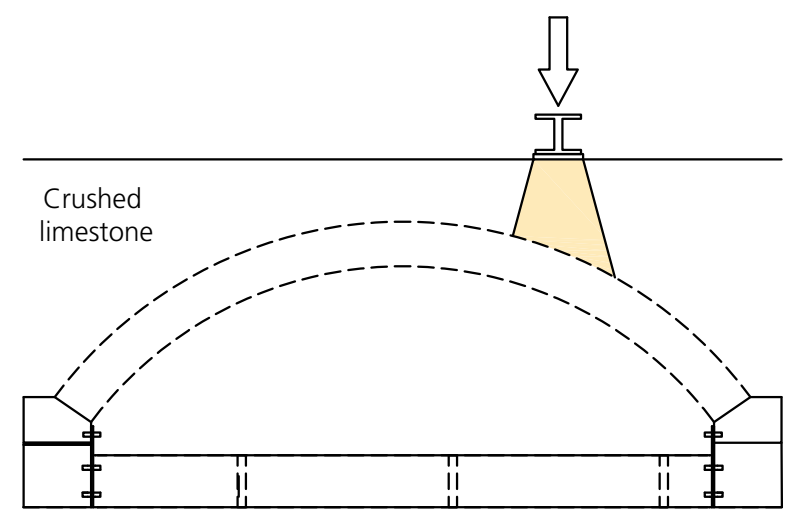

(a)

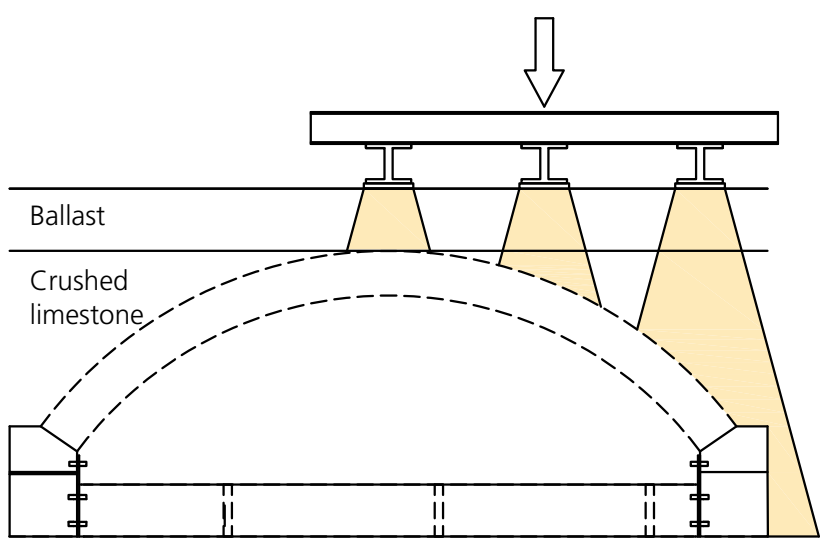

(b)

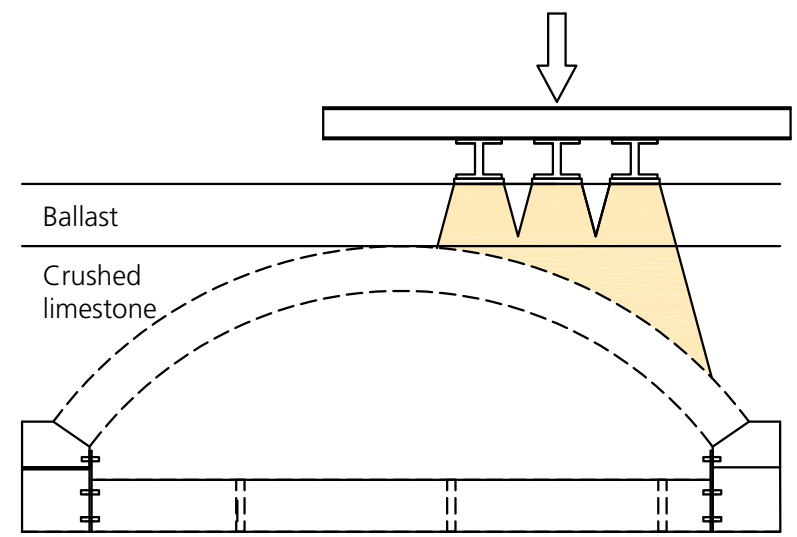

(c)

Figure 8. Load distribution: (a) EP1-PH1 and EP1-PH2; (b) EP3-PH1 and EP3-PH2; (c) EP3-PH3. A 1:4 slope $\left(15^{\circ}\right)$ was considered for illustration purposes image analysis presented later in this paper does support this observation.

Figure 9 shows the failure mechanisms observed in the tests. Figure 9(a) shows that the failure mechanism of the highway arch EP1 took on the classical four-hinge form with minor movement of the west abutment during initial loading. Figure 9(b) shows the observed failure mechanism for the rail arch for the first two rail arch load tests (EP3-PH1 and PH2). In these tests, three hinges formed at the locations indicated (A, B and C), while sliding of the west skewback was also observed. Figure 9(c) shows the mechanism for the third load test on EP3 (EP3-PH3), which indicates that failure reverted to a fourhinge mechanism with hinges at the locations indicated (A-D). Crack formation observed in the arch barrel indicated that the hinge adjacent to the west skewback developed to a small degree during these first two load tests, but was not significant. The hinge positions in EP3-PH3 were different from those in EP1-PH2, showing the influence of the loading configuration and loading/deformation history.

From the evidence presented by the test results it would appear that the load-carrying capacity is influenced by the failure mechanism that forms within the arch, as well as by the soil resistance to deformation of the arch on the passive side.

In the first rail load test (EP3-PH1), the first hinge formed at point B (Figure 9(b)), directly beneath the load, followed by the formation of hinges at points A and C. Initially, movement of the mortar joint between the western abutment and the overlying skewback was associated with some opening of the joint with possible rotation. Sliding along this joint was initiated at a load of around $100 \mathrm{kN}$. Negligible sliding was observed for the east abutment. The extent of the movement in the west abutment is illustrated in Figure 10, which compares the displacements of the abutment for the rail arch and the highway arch directly and shows the rate of horizontal movement on this joint as a function of the quarter-span deflection. In the load test on the highway arch, skewback movement peaked at around $5 \mathrm{~mm}$ whereas, in the load tests on the rail arch, skewback movement peaks at around $35 \mathrm{~mm}$, admittedly with significant quarter-span deflection. The fact that the skewback stopped moving in EP1 at a peak of $5 \mathrm{~mm}$ supports the contention that, initially, the arch failed through the formation of three hinges and sliding at the abutment. Once the peak load was reached, the skewback stopped sliding and a fourth hinge formed at point D in Figure 9(a). As might be expected, in the second load test on the highway arch, no further sliding was observed and the arch failed with the formation of four hinges at the locations indicated in Figure 9(a).

In the rail arch test, again, the failure mechanism appeared to be three hinges and sliding at the abutment for both the first 


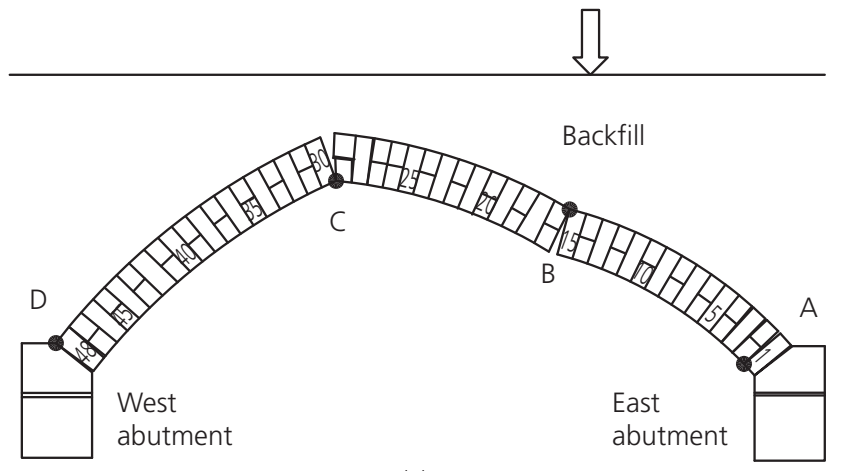

(a)

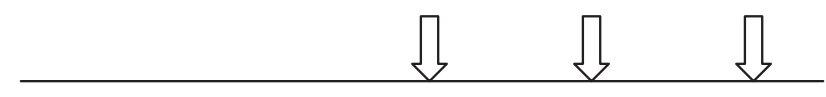

Backfill
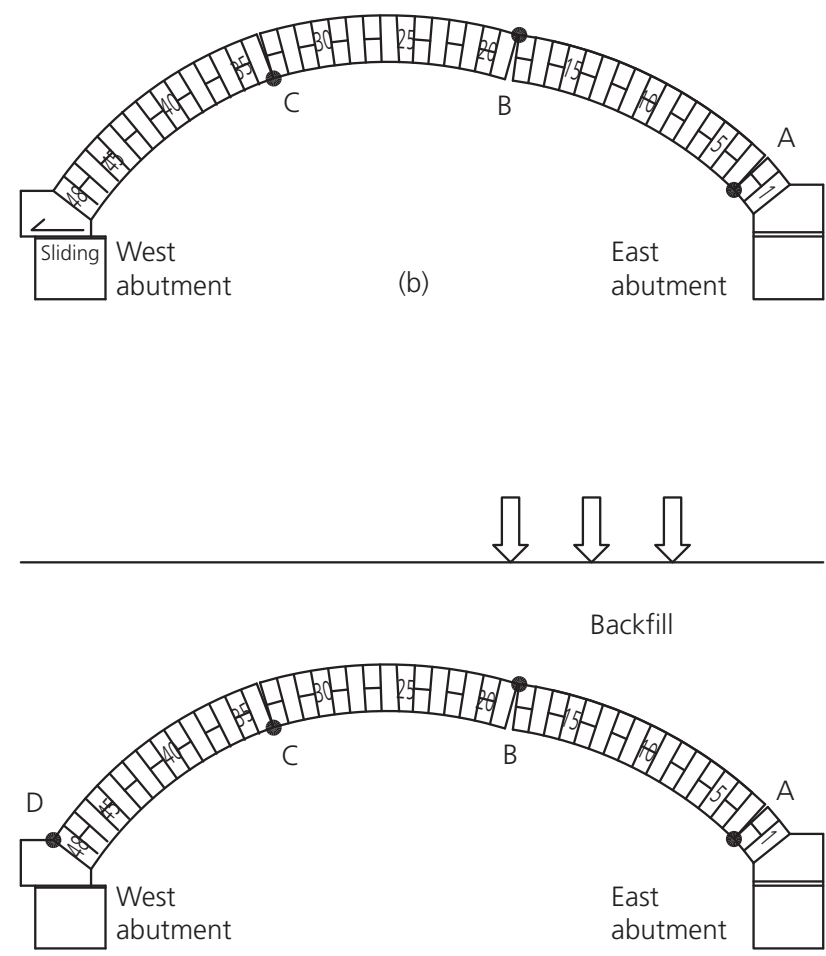

(c)

Figure 9. Observed failure mechanisms: (a) four-hinge mechanism in EP1-PH1 and EP1-PH2; (b) three-hinge plus sliding mechanism in EP3-PH1 and EP3-PH2; (c) four-hinge mechanism in EP3-PH3 (deformations magnified by ten from those measured at the end of the test phase)

load test and the second load test. However, Figure 10 indicates that, at a quarter-span deflection of around $60 \mathrm{~mm}$, not only was the peak load reached, but sliding of the skewback

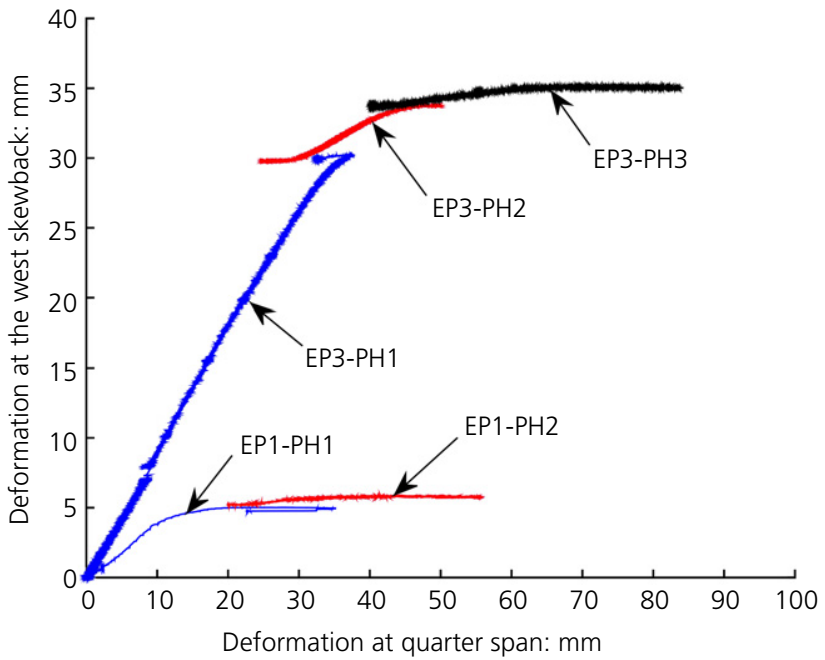

Figure 10. Deformation at the west skewback against deformation at the quarter-span

also stopped, indicating that a fourth hinge had formed in the arch at point D. It is not clear whether this was the maximum movement that would have been achieved through the EP3PH1 and EP3-PH2 loading configuration or whether it was influenced by the change in loading configuration in EP3$\mathrm{PH} 3$; this needs further investigation. However, the nature of the curve for EP3-PH2 indicates that it would have been fairly close to this value.

Image analyses of the highway and railway arch tests are presented in Figure 11. Figure 11(a) shows the soil deformation beneath the applied load and around the arch barrel during the first load test carried out under highway loading, while Figures 11(b) and 11(c) show this for the first load test and third load test on the rail arch, respectively.

In EP1-PH1, the load was applied as a line load above the quarter-span, and the vectors indicate the predominantly downward vertical movement of the soil beneath this load towards the arch (Figure 11(a)). Localised rotation of the arch around the mid-span is also shown in this figure, caused by the four-hinge failure mechanism discussed earlier.

Figure 11(b) indicates that significant horizontal movement of the west skewback accompanied the formation of three hinges in the arch barrel. Since the vertical load was applied to the soil through a longitudinal rail placed on the sleepers, the soil was largely confined beneath the sleepers and so longitudinal rather than vertical movement of the soils was predominate. Once the sleeper spacing was reduced, as in the third rail arch load test, the zone of confinement was also reduced, allowing the soil to displace vertically as the arch rotated, as shown in Figure 11(c). 

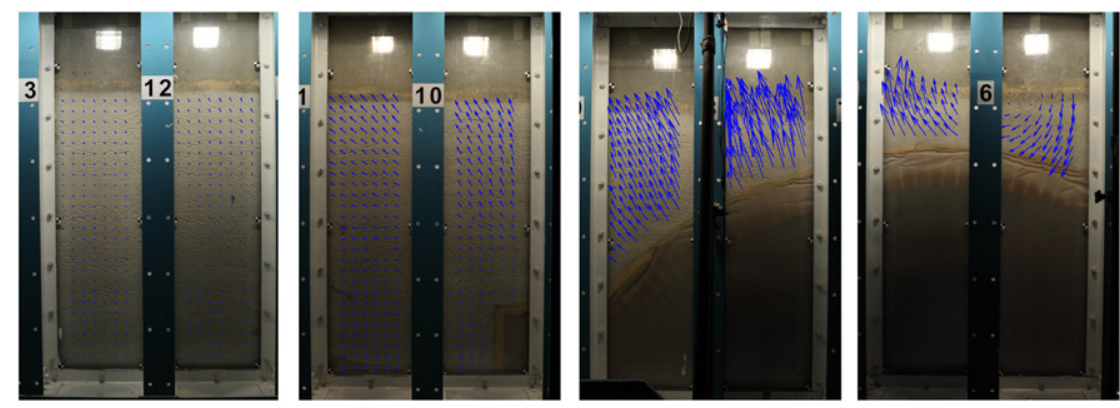

(a)
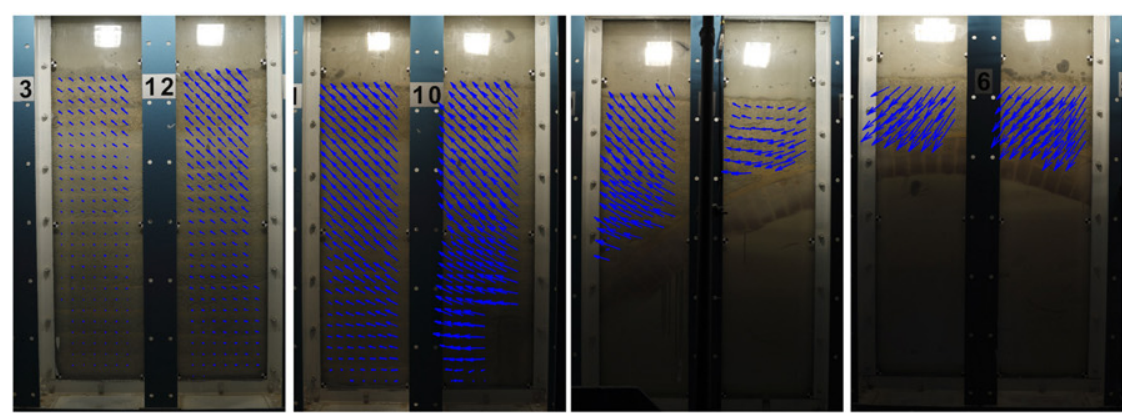

(b)
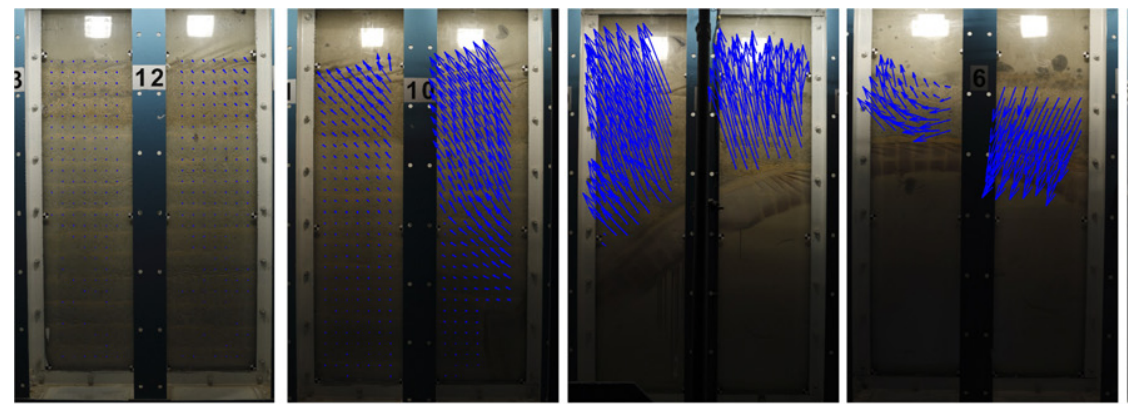

(c)
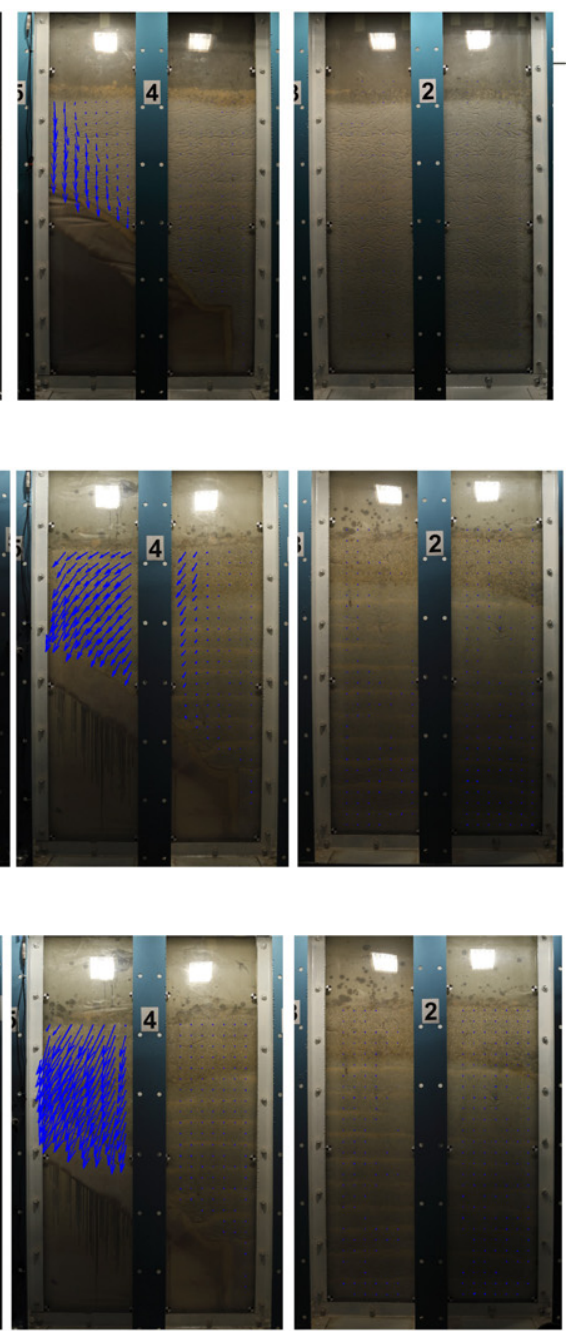

Figure 11. Results of PIV analysis showing soil kinematics: (a) EP1-PH1; (b) EP3-PH1; (c) EP3-PH3

The changes in pressure recorded by the pressure cells located in the extrados of the arch barrel were used to interpret the soil-structure interaction and the influence of applied load qualitatively. Figure 12 shows the build-up of pressure on the arch barrel during the first quasi-static load tests on EP1 and EP3. During the highway load test (Figure 12(a)), as might be expected, the pressure on the arch barrel was highest directly beneath the loading beam (PC4). Some passive pressure (of the order of $30-50 \mathrm{kPa}$ at failure) developed as the arch deformed into the surrounding backfill under this applied load.

The picture was a little less distinct for the rail arch (Figure 12(b)) due to the confinement provided by the rail loading arrangement. Initially, the arch barrel directly beneath the load experienced the highest pressures but as the applied load increased the arch rotated around the hinge at point $\mathrm{B}$
(Figure 9(b)), close to pressure cell PC5. This hinging led to lower pressures at PC5 and much higher pressures on the arch barrel close to the crown (PC6 and PC7 either side of the crown). Overall, the loading pressures were distributed over the east half of the arch, as expected. Passive pressures were slightly lower than those in EP1-PH1 at the equivalent EP1-PH1 peak load of $140 \mathrm{kN}$ and remained lower as a proportion of the applied load; this is attributed to significant passive pressures also being mobilised adjacent to the sliding abutment.

\section{Numerical modelling}

Ultimate limit state models of the tested arches were established using the discontinuity layout optimisation (DLO) procedure (Gilbert et al., 2007) as implemented in the LimitState:GEO software (LimitState, 2014). This solution procedure provides results in the form of the optimal upper bound slip-line 


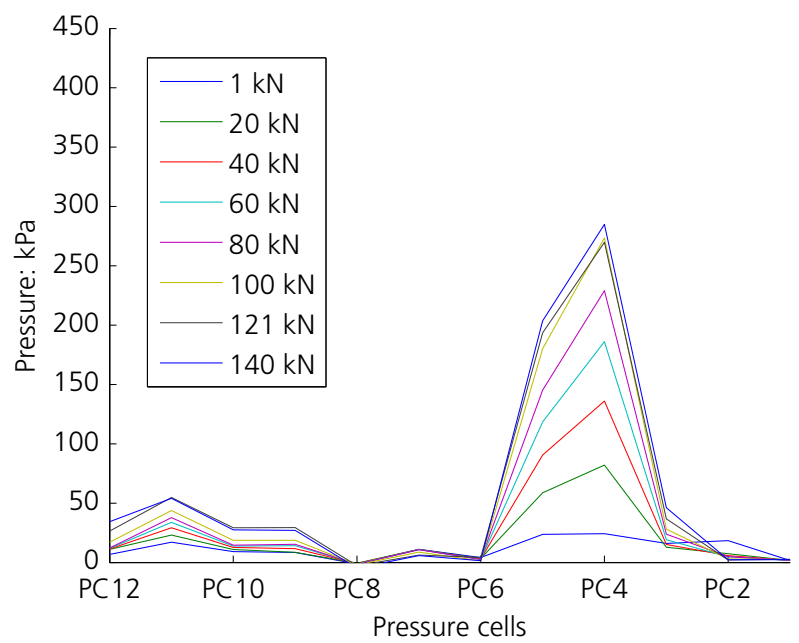

(a)

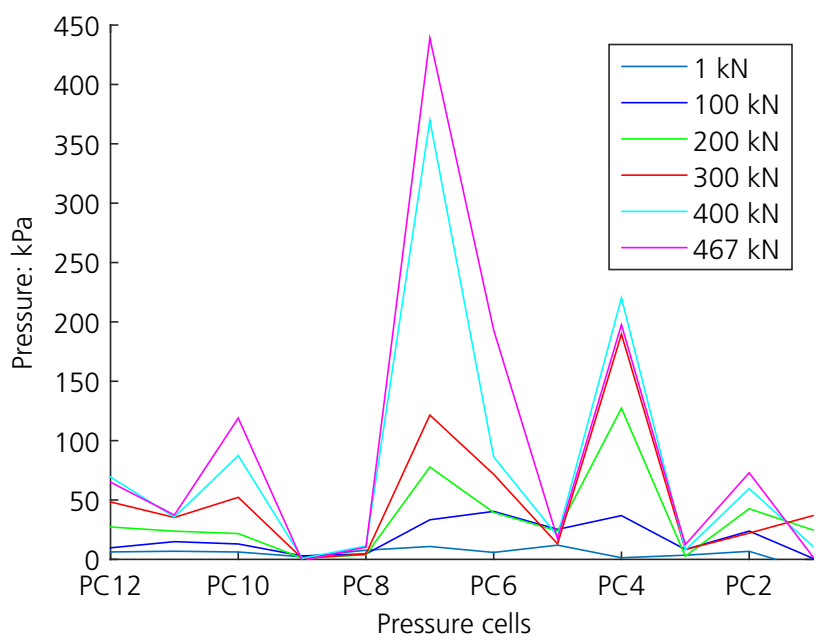

(b)

Figure 12. Pressure on the arch barrel during quasi-static loading testing: (a) EP1-PH1; (b) EP3-PH1 (note the different contour intervals in each plot)

mechanism (to a specified resolution) and corresponding collapse load for a given input loading geometry, and strength and self-weight properties of the soil and masonry. Descriptions of typical model set ups in this software and the modelling methodology have been extensively described previously (e.g. Callaway et al., 2012; Gilbert et al., 2010)) and are thus not repeated here. Standard software defaults were used unless otherwise stated. The key modelling parameters are listed in Table 3. The ballast was modelled with the same strength as the limestone fill. Typical strength parameters for ballast in the literature report a friction angle varying from $45^{\circ}$ to $55^{\circ}$. Choice of the equivalent limestone fill strength at the upper end of this scale produced kinematics similar to those seen in the PIV, while numerical modelling of lower strengths led to some local bearing failure in the upper layer that was not observed in the experiments.

The aim of this modelling was to provide additional insight into the experimental results that were observed rather than

Table 3. Parameters used in the LimitState:GEO models

\begin{tabular}{ll} 
Parameter & Value \\
\hline Height of fill above crown & $300 \mathrm{~mm}$ \\
Ballast depth (EP3) & $300 \mathrm{~mm}$ \\
Ballast unit weight & $16 \cdot 4 \mathrm{kN} / \mathrm{m}^{3}$ \\
Limestone unit weight & $20 \mathrm{kN} / \mathrm{m}^{3}$ \\
Limestone strength & $\mathrm{c}^{\prime}=3 \cdot 3 \mathrm{kN} / \mathrm{m}^{2}, \phi^{\prime}=54.5^{\circ}$ \\
Loading beam bending strength & $85 \cdot 1 \mathrm{kN} \cdot \mathrm{m} / \mathrm{m}$ \\
Skewback angle to horizontal & $36.9^{\circ}$ \\
Active zone mobilisation & 1.0 \\
Passive zone mobilisation & Variable \\
Soil/arch interface friction multiplier & 0.66 \\
Soil/loading beam interface friction & 0.66 \\
$\quad$ multiplier &
\end{tabular}

undertaking an in-depth numerical and parametric study. These models therefore focused on the dramatic increase in capacity of the rail-loaded arches and the change in failure mode.

The three LimitState:GEO models utilised for EP1-PH1, EP3PH1 and EP3- PH3 are depicted in Figure 13. For all the PH2 and $\mathrm{PH} 3$ tests, the original arch geometry was utilised rather than the deformed geometry, the latter being beyond the scope of the current work as it requires detailed consideration of the distorted geometry including cracks that may have been infilled with soil. Rail loading was modelled using a conventional (1/4):(1/2):(1/4) load split as well as with a beam element with the same plastic moment of resistance as the beam employed in the physical models, and, for comparison, a fully rigid rail. This enabled evaluation of the conventional loading model. It should also be noted that in the EP3 rail loading models, the passive side failure mechanism intersected the ends of the model domain (which corresponded to the test tank dimensions). This was due to the three-hinge plus abutment sliding mechanism dominating in these tests, which mobilised a larger volume of 'passive' soil than the four-hinge mechanism for which the tank was originally designed. Additional LimitState:GEO models were built with an extended domain and the results varied by less than $1 \%$, while the passive wedge extended less than $10 \%$ further into the additional unconstrained space. It was therefore assumed that this effect was insignificant.

Table 4 shows that the significant increase in rail loading capacity with loading width observed in the experiments could be predicted using numerical analysis. All three tests showed a 


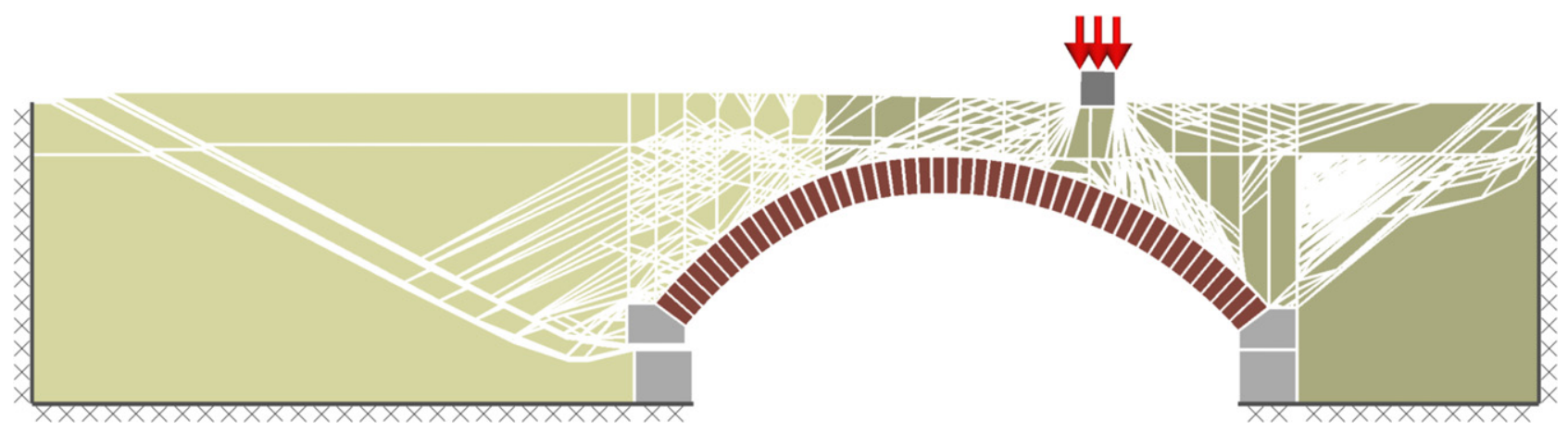

(a)

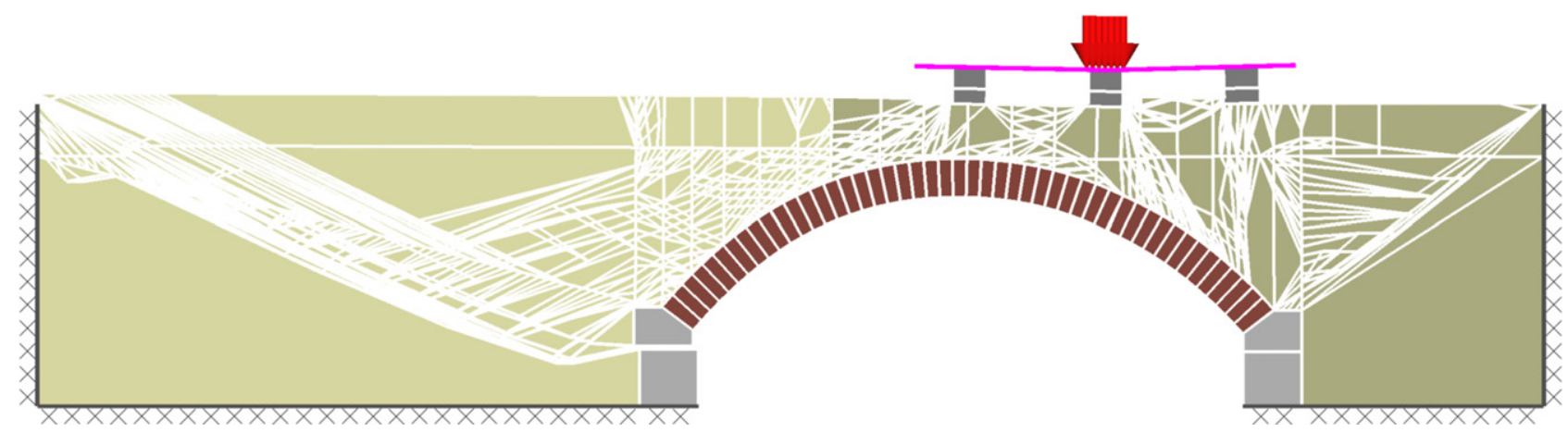

(b)

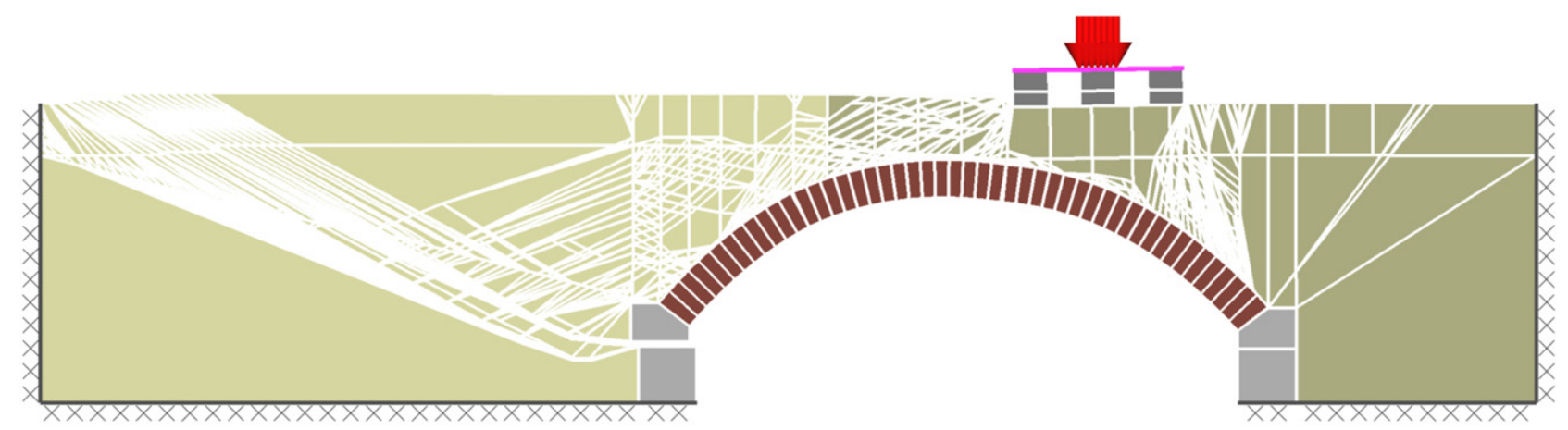

(c)

Figure 13. LimitState:GEO models of test arches: (a) EP1-PH1 (0.50); (b) EP3-PH1 (0.66); (c) EP3-PH3 (0.50); the values in brackets indicate the modelled mobilisation of passive pressure

failure mechanism that was a combination of a four-hinge mechanism and a three-hinge plus sliding mechanism, with the latter becoming more dominant with an increase in loading width, which is consistent with the experimental observations. It is not possible to correlate the PIV image analysis results in Figure 11 directly with the mechanisms in Figure 13 since the former are 'averaged' over a range of loadings whereas the latter are 'instantaneous' mechanisms selected to give the closest match in predicted peak load. These mechanisms typically indicated three-hinge plus sliding behaviour. However, the wider set of numerically generated mechanisms show good consistency, for example indicating the transition to a fourhinge mechanism for EP1 as greater passive soil strength was mobilised, as shown in Figure 11(a).

The wider rail loading tended to suppress the four-hinge mechanism since it would lead to the right-hand sleeper moving upwards and the load would be working against itself. The system therefore finds it easier to slide the right-hand abutment block despite this moving a larger volume of 'passive' soil than in the four-hinge mechanism, implying that less energy is required to overcome the sliding resistance at the skewback 
Table 4. Comparison of experimental (exp.) and numerical (DLO) data

\begin{tabular}{|c|c|c|c|c|c|c|c|}
\hline \multirow[b]{2}{*}{ Test phase } & \multirow[b]{2}{*}{ Exp.:kN } & \multicolumn{2}{|c|}{ Mobilisation $=0.33$} & \multicolumn{2}{|c|}{ Mobilisation $=0.50$} & \multicolumn{2}{|c|}{ Mobilisation $=0.66$} \\
\hline & & DLO: kN & DLO/Exp. & DLO: kN & DLO/Exp. & DLO: kN & DLO/Exp. \\
\hline \multicolumn{8}{|l|}{ EP1 } \\
\hline PH1 & 140 & 114 & $0 \cdot 81$ & 168 & $1 \cdot 20$ & 235 & 1.68 \\
\hline \multicolumn{8}{|l|}{ EP3 } \\
\hline PH1-750-1-2-1 & 470 & 223 & 0.47 & 335 & 0.71 & 504 & 1.07 \\
\hline PH1-750-rail & 470 & 257 & 0.55 & 394 & 0.84 & $539^{a}$ & $1 \cdot 15^{a}$ \\
\hline PH1-750-rail-R ${ }^{b}$ & 470 & 257 & 0.55 & 394 & 0.84 & 597 & $1 \cdot 27$ \\
\hline \multicolumn{8}{|l|}{ EP3 } \\
\hline PH3-375-1-2-1 & 280 & 168 & $0 \cdot 60$ & 250 & 0.89 & 372 & 1.33 \\
\hline PH3-375-rail & 280 & 179 & 0.64 & 267 & 0.95 & 395 & $1 \cdot 41$ \\
\hline PH3-375-rail-R ${ }^{b}$ & 280 & 179 & 0.64 & 267 & 0.95 & 395 & 1.41 \\
\hline
\end{tabular}

${ }^{a}$ Rail bent. Interface coefficient $=0.66$.

${ }^{b} \mathrm{R}$, rigid rail modelled

interface and the soil strength in this zone than in overcoming the (increasing) confining pressures.

In addition, the numerical modelling implies that there was greater mobilisation of soil strength in the passive zone as the failure mode tended towards a three-hinge plus sliding mechanism. As shown in Table 4, the numerical models gave the best fit to the experimental data with the mobilisation increasing from $\sim 0.4$ to 0.6 as the loading width changed from highway loading $(200 \mathrm{~mm}$ ) to rail loading, $\sim 950 \mathrm{~mm}$ and then $\sim 1700 \mathrm{~mm}$. This can be explained by the larger overall arch displacement needed to attain peak arch capacity (i.e. for the arch on its own as a structure) for a three-hinge plus sliding mechanism when compared with a four-hinge mechanism.

The results show that the (1/4):(1/2):(1/4) conventional load split model generally provided a good fit while being conservative compared with explicit modelling of a beam or rail across the sleepers. This split is close to that predicted by the numerical models, which varied from $25 \%: 50 \%: 25 \%$ to $28 \%: 44 \%: 28 \%$ in cases where there was separate failure beneath each sleeper. Where the soil failed as a rigid block beneath all three sleepers (see Figure 13(c) for example), the loading remained nearly symmetrical (about $3 \%$ off centre).

\section{Discussion}

It is clear that abutment sliding permits a more beneficial three-hinge plus sliding mechanism compared with a simple four-hinge mechanism. The former has an extended ductile response whereas the latter displays peak strength at relatively low displacements. As shown by the numerical modelling, in reality the failure mode will be a superposition of the two. In the EP1 experimental tests an initial three-hinge plus sliding mode was observed which then metamorphosed into a fourhinge mechanism as increasing passive strengths were mobilised. The LimitState:GEO models were not able to capture the gross displacement aspect of this and predicted a combination of the two modes. However, simulations utilising higher passive mobilisations predicted a simple four-hinge mode from the start.

In the quasi-static tests, loading was restricted to three sleepers. In reality, loading will actually be spread further over sleepers across the full bridge span, so it is anticipated that the significant capacity gains seen in these experiments are likely to be conservative. However, at some stage, the rail/beam will suffer plastic bending that will limit the load distribution effect. Further work is required to explore this issue.

It was observed that the four-hinge mechanism due to road loading required a relatively small $(10 \mathrm{~mm}$ for the arch tested) quarter-span movement to mobilise peak strength, while the three-hinge plus sliding mechanism required a significantly larger displacement to mobilise maximum strength. However, the strength mobilised at $10 \mathrm{~mm}$ displacement for the latter mechanism was still significantly larger than that for road loading.

The load tests conducted on damaged arches under both rail and highway loading conditions indicated that the residual capacity of such structures is also significant and should not be overlooked, being $90-100 \%$ of the original arch capacity for those arches tested. This area requires further investigation to establish what damage geometry remains stable under continued service loading, but evidence from the field indicates continued long-term performance of significantly distorted arches.

\section{Conclusions}

Results of experimental work involving large-scale physical modelling of backfilled masonry arch bridges subjected to highway and railway loading conditions were presented in this paper. A highway and a railway masonry arch bridge with 
near-identical construction details and applied loading regimes were load tested, enabling investigation of the influence of the railway track-bed system on bridge behaviour and capacity.

Both bridges were subjected to cyclic loading in order to replicate the service loading conditions that such bridges would be likely to experience in practice. Loading was at a relatively low level that did not damage the bridges, but did allow densification of the fill around the arch barrel. The arch bridges were then subjected to quasi-static tests until failure.

The results of this work indicate that the load-carrying capacity of a short-span railway masonry arch bridge will be significantly higher than that of an equivalent highway bridge, with a factor of up to $\approx 3$ observed in the case of the two bridges tested. This is largely attributable to the increased confinement provided by the combination of a continuous rail and sleepers. In addition, it was observed that this confinement may also influence the failure mechanism; in particular, for railway masonry arch bridges, a three-hinge mechanism combined with sliding along the skewback was observed. Although this combination was also initially observed for the bridge subjected to highway loading conditions, at the peak load, the mechanism switched to one involving four hinges with no further sliding on the skewback. The observations were supported by numerical analyses and PIV analysis of high-quality digital images captured at various stages of the load tests that showed the soil kinematics beneath the applied load and around the deforming arch barrel.

The load tests conducted on damaged arches under both rail and highway loading conditions indicated that the residual capacity of such structures is also significant $(90-100 \%$ of the original load-carrying capacity for the bridges tested) and should not be overlooked.

\section{Acknowledgements}

The authors acknowledge the support of the UK Engineering and Physical Sciences Research Council, under grant references EP/I014357/1 and EP/I014489/1. The contribution of Dr Sam Hawksbee, who undertook a number of preliminary numerical simulations, is also acknowledged.

\section{REFERENCES}

Augusthus-Nelson L, Swift G, Melbourne C, Smith C and Gilbert M (2018) Large-scale physical modelling of soil-filled masonry arch bridges. International Journal of Physical Modelling in Geotechnics 18(2): 1-14.

Brencich A and De Francesco U (2004) Assessment of multispan masonry arch bridges. II: examples and applications. Journal of Bridge Engineering 9(6): 591-598.

Callaway P, Gilbert M and Smith CC (2012) Influence of backfill on the capacity of masonry arch bridges. Proceedings of the Institution of
Civil Engineers - Bridge Engineering 165(3): 147-157, https://doi.org/10.1680/bren.11.00038.

Gilbert M, Nguyen DP and Smith CC (2007) Computational limit analysis of soil-arch interaction in masonry arch bridges. In Proceedings of the 5th International Conference on Arch Bridges, Madeira, vol. 7 , pp. 633-640.

Gilbert M, Smith CC and Pritchard TJ (2010) Masonry arch analysis using discontinuity layout optimisation. Proceedings of the Institution of Civil Engineers - Engineering and Computational Mechanics 163(3): 155-166, https://doi.org/eacm.2010.163.3.155.

Hughes TG and Blackler MJ (1997) A review of the UK masonry arch assessment methods. Proceedings of the Institution of Civil Engineers - Structures and Buildings 122(3): 305-315, https://doi.org/10.1680/istbu.1997.29801.

Kennedy J, Woodward PK, Medero G and Banimahd M (2013) Reducing railway track settlement using three-dimensional polyurethane polymer reinforcement of the ballast. Construction and Building Materials 44: 615-625.

LimitState (2014) LimitState: GEO Manual, Version 3. LimitState, Sheffield, UK.

Melbourne C and Gilbert M (1995) The behaviour of multiring brickwork arch bridges. The Structural Engineer 73(3): 39-47.

Molins C and Roca P (1998) Capacity of masonry arches and spatial frames. Journal of Structural Engineering 124(6): 653-663.

Network Rail (2006) The Structural Assessment of Underbridges. Network Rail, London, UK, Guidance Note NR/GN/CIV/025.

Orbán Z (2007) UIC project on assessment, inspection and maintenance of masonry arch railway bridges. ARCH 7: 3-12.

Orbán Z and Gutermann M (2009) Assessment of masonry arch railway bridges using non-destructive in-situ testing methods. Engineering Structures 31(10): 2287-2298.

Swift GM, Augusthus Nelson L, Melbourne C and Gilbert M (2013) Physical modelling of cyclically loaded masonry arch bridges. Proceedings of 7th International Conference on Arch Bridges, Split, Croatia, pp. 621-628.

UIC (International Union of Railways) (1994) Leaflet 774-2R Distribution of Axel-Loads on Ballasted Railway Bridges. UIC, Paris, France.

White DJ and Take WA (2002) GeoPIV: Particle Image Velocimetry (PIV) Software for Use in Geotechnical Testing. Cambridge University Engineering Department, Cambridge, UK, Technical report CUED/D-SOILS/TR322.

\section{How can you contribute?}

To discuss this paper, please email up to 500 words to the editor at journals@ice.org.uk. Your contribution will be forwarded to the author(s) for a reply and, if considered appropriate by the editorial board, it will be published as discussion in a future issue of the journal.

Proceedings journals rely entirely on contributions from the civil engineering profession (and allied disciplines). Information about how to submit your paper online is available at www.icevirtuallibrary.com/page/authors, where you will also find detailed author guidelines. 